\title{
The MUP Zagros Project: tracking the Middle-Upper Palaeolithic transition in the Kermanshah region, west-central Zagros, Iran
}

\author{
Saman Heydari-Guran ${ }^{1,2, *} \&$ Elham Ghasidian ${ }^{1,2}$
}

\section{Introduction}

In recent decades, the Eurasian Middle-Upper Palaeolithic (M-UP) transition has been a topic of major interest among palaeoanthropologists. Great progress has been made in several domains, particularly palaeogenetics, which have revealed the complex ancestry of early Eurasians. This progress - including the identification of a ghost lineage of Eurasians in the Middle East-is providing important new biogeographical hypotheses. A key region for such topics is the Iranian Plateau - an area that has so far not been subject to intensive research. The Kermanshah region, located between the Mesopotamian lowlands to the west and the high plateau to the east, provides relatively easy passage onto the Iranian Plateau (Heydari-Guran 2015) (Figure 1). The long history of Palaeolithic research in the westcentral Zagros Mountains has revealed a number of sites associated with M-UP assemblages (Smith 1986 and references therein). In addition, occasional reports of new discoveries or re-analysis of old collections (Shidrang et al. 2016) illustrate the richness and potential for hominin occupation during the Upper Pleistocene and, more specifically, the M-UP transition. Among these, Warwasi (Figure 1) is an exceptional case, as it has yielded a long Middle-Epipalaeolithic sequence (e.g. Olszewski \& Dibble 1994). While some researchers have proposed a model of gradual change from the Middle-Upper Palaeolithic, re-analysis of the Warwasi collection suggests that the Upper Palaeolithic industry at this site is intrusive to the region rather than a local evolution from the Middle Palaeolithic (Tsanova 2013).

Despite such evidence, our knowledge of Palaeolithic occupation in this region (indeed, in the entire Iranian Plateau) still suffers from a lack of systematic, up-to-date and scientific work (Heydari-Guran 2014). Smith (1986: 41-42) has correctly pointed to issues such as the lack of reliable stratigraphy and site-formation analyses, accurate absolute dating and detailed studies of lithic artefacts, raw materials, faunal remains and settlement. Further,

1 Leverhulme Centre for Human Evolutionary Studies, Department of Archaeology and Anthropology, University of Cambridge, Fitzwilliam Street, Cambridge CB2 1QH, UK

2 Diyarmehr Institute for Palaeolithic Research, 1 Awesta Street, Kermanshah, PO 78144-67189, Iran

* Author for correspondence (Email:sh911@cam.ac.uk) 




Figure 1. Map showing the location of the Kermanshah region within the west-central Zagros Mountains, with Palaeolithic sites and the places that are mentioned in the text (shown as stars). 
the analysis of lithic artefacts that has been undertaken is complicated by the divergent approaches of different schools to techno-typological descriptions.

The MUP Zagros Project aims to track the Upper Pleistocene hominin occupation and M-UP cultural and behavioural transition in the Kermanshah region. The first aim is to collate a dataset, at various spatial scales, that will contribute to broader discussions on the nature and evolution of so-called behavioural modernity and the eastern migration of early humans out of Africa via the Zagros Mountains. These data will allow the authors to analyse the study region in detail and to compare it with the cultural traditions of Southwest Asia more generally.

The second aim is to excavate at key sites to obtain reliable absolute dates and to examine raw material procurement and site-formation processes. A chainne opératoire approach will be employed to analyse lithic artefacts, and the study of raw materials will focus on lithic types, procurement strategies and geographic distributions, seeking changes between the Upper Palaeolithic and Middle Palaeolithic. The transition between these two periods will also be informed by analysis of depositional processes of occupation layers using micromorphology to identify formation sequences and (dis)continuities.

The third aim is the re-analysis of collections from older excavations. We plan to conduct a techno-typological analysis for the lithic assemblages from several excavated sites, including the large collection from the Warwasi rockshelter.

\section{Archaeological and environmental surveys}

The first phase of the project includes archaeological and environmental surveys covering an area of around $150 \times 100 \mathrm{~km}$ (Figure 1). The region is divided into four geo-ecological zones:

A. The marginal area consisting of alluvial formations between the Zagros Mountains and the low-lying plain of Mesopotamia, less than $300 \mathrm{~m}$ asl.

B. The lower Zagros Mountains including small and narrow intermontane valleys, around $300-500 \mathrm{~m}$ asl, surrounded by mountains up to $1200 \mathrm{~m}$ asl.

C. High intermontane plains, $1300-1500 \mathrm{~m}$ asl, surrounded by hills and high folded mountains up to $2500 \mathrm{~m}$ asl.

D. Large intermontane plains around $1300 \mathrm{~m}$ asl surrounded by karstic and steep high mountains from $2000-3500 \mathrm{~m}$ asl.

Our survey identified 265 caves, rockshelters and open-air sites associated with archaeological finds (Figure 1), including over 7000 Middle Palaeolithic-Epipalaeolithic artefacts. We also revisited 39 sites that had been previously recorded (Heydari 1999; Biglari \& Shidrang 2016: 29 and references therein). Although the sites are distributed across all four zones, several areas have higher concentrations, including those with marshes, highcontrast topography, strategic corridors and raw material outcrops. In addition, the larger caves and rockshelters with greater accumulations of natural and archaeological deposits are found in karstic zone D. 

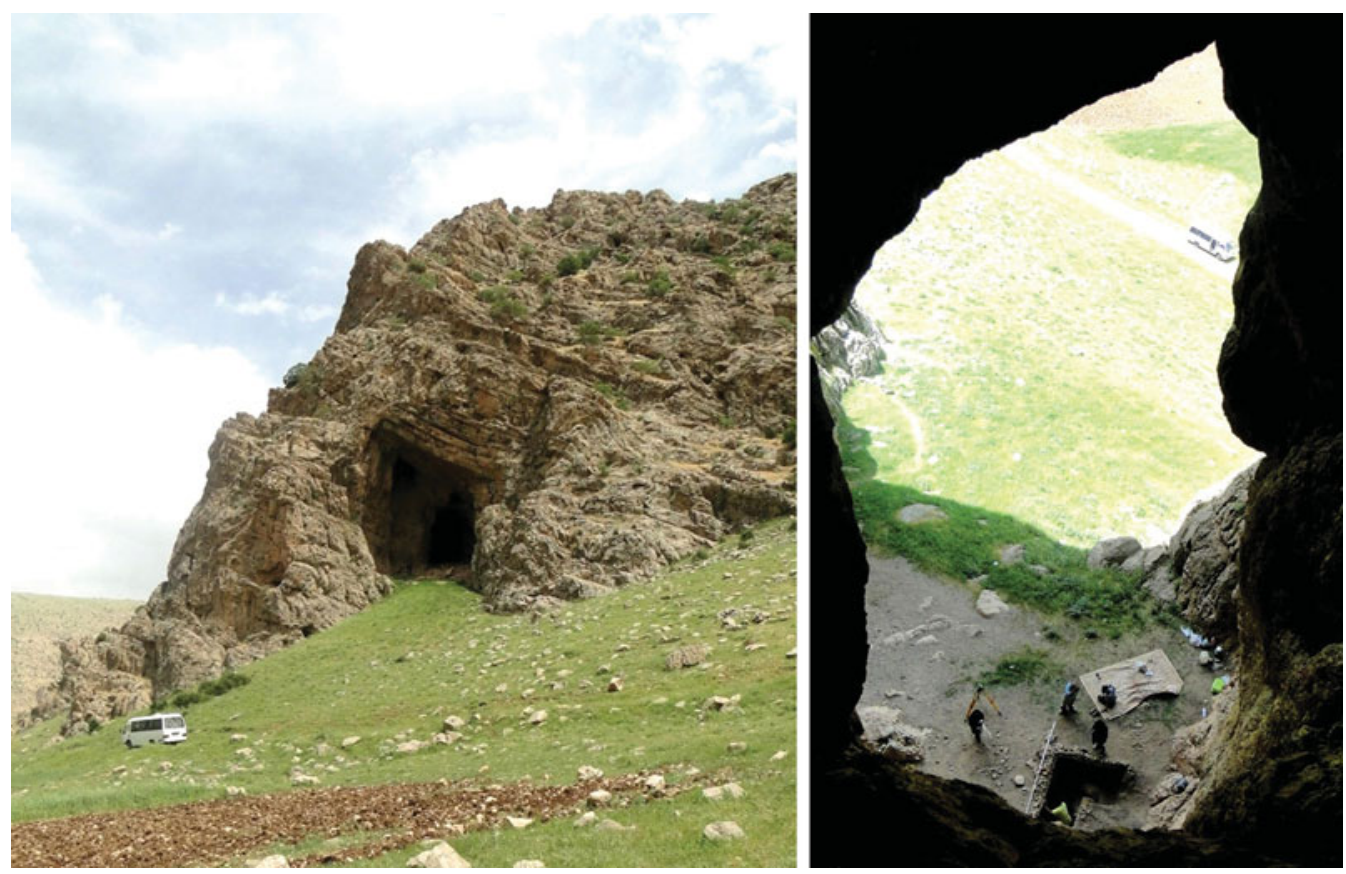

Figure 2. Eshkaft-e Razawar: view from outside, inside and the position of the recent archaeological trench.

\section{Excavations}

Three sites-Tutan, Eshkaft-e Razawar and Yawan, all in the Razawar Valley (Figures 1 \& 2) —were selected for excavation. Parts of these sites have been damaged by clandestine activity or development, both of which are issues that have unfortunately and dramatically increased in recent years in Iran, especially affecting caves and rockshelters. Exposed sections were cleaned and trenches were opened near to the exposed deposits.

A test trench was dug in a small cave at Tutan (Figures $1 \& 3$ ). The site contains at least three distinct archaeological horizons: I-III. The uppermost, horizon I, appears to be a mixture of Holocene and late Pleistocene deposits, while the two deeper archaeological horizons contain intact Pleistocene deposits with Palaeolithic materials. There are clear changes between the horizons of II (Upper Palaeolithic) and III (Middle Palaeolithic). Although the trench at Tutan is small, horizons II and III have yielded a large number of lithic artefacts including Middle Palaeolithic unifacial points on Levallois flakes (Figure 4). They are long, with thin cross-sections, having been heavily modified, and are reminiscent of Zagros Mousterian points. The Upper Palaeolithic artefacts, recovered largely from horizon II, are mostly laminar and have Baradostian characteristics. A relatively wellpreserved faunal assemblage from horizons II and III includes ungulates, including wild forms of cattle (Bos primigenius), onager or ass (Equus hemionus), goat (Capra sp.) and European hare (Lepus europaeus).

A second test trench was excavated at the Eshkaft-e Razawar Cave (Figures 1 \& 2). A $2.5 \mathrm{~m}$-deep test trench exposed three archaeological strata including Holocene and (C) Antiquity Publications Ltd, 2017 


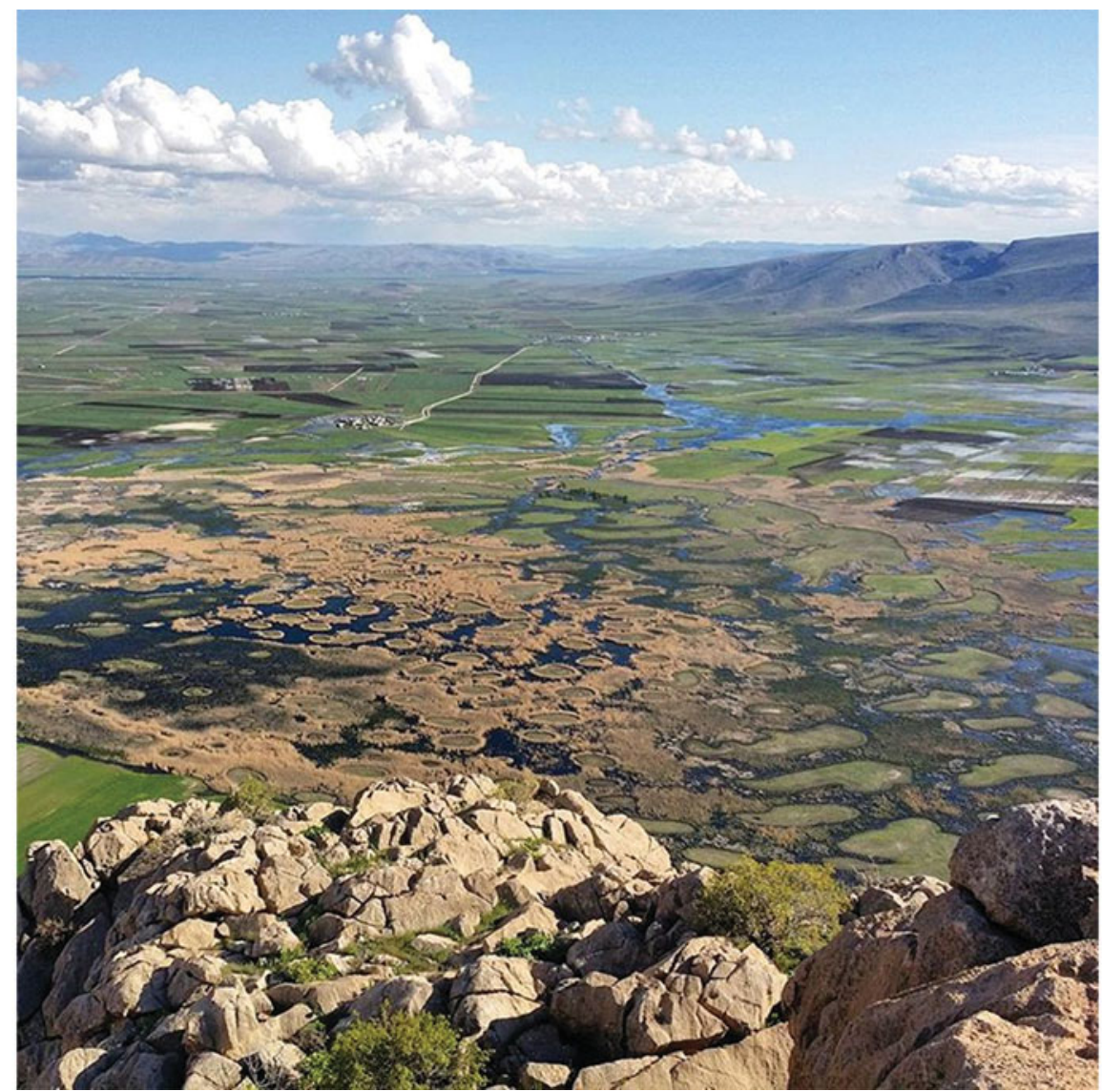

Figure 3. Hashilan marshland in the Razawar Valley (photograph by Ali Kurd, 2016).

Pleistocene deposits containing several well-preserved hearths associated with bones and lithic artefacts. Several charcoal samples have been dated, with results of 4709 cal BP (laboratory code OxA-X-2660-36; at 95.4\% probability) for the Holocene deposits and a range of dates from 30900-39800 cal BP (laboratory code OxA-X-33260, OxA-X2659-43; at $95.4 \%$ probability) from the top to the bottom of the Pleistocene layers. The preliminary techno-typological analyses of the lithic artefacts from the Pleistocene horizons show that those from the upper layer are typically Upper Palaeolithic, and that those from the lower are typically Levalloisian Middle Palaeolithic. The dates of the Middle Palaeolithic deposits suggest that the Levallois culture was present until at least $40 \mathrm{kyr}$ BP at this site. The first results of the faunal analysis indicate CapralOvis and bones from a large bovid or equidae, as well as small ungulates and birds. A first phalanx of CapralOvis in the Upper Palaeolithic layer has a cut mark.

A third excavation was conducted at the Yawan rockshelter. During a survey in 2009, we noted disturbance caused by road construction, resulting in the unearthing of a large number of lithic artefacts, mostly Upper Palaeolithic. In March 2016, a $2 \times 4 \mathrm{~m}$ trench was opened near the shelter wall. At its deepest point, the trench reached $2.8 \mathrm{~m}$ with two 




Figure 4. A collection of the lithic artefacts from Tutan Cave.

main archaeological horizons (Upper Palaeolithic and Middle Palaeolithic) recorded. Part of the deposits had been transformed into a semi-travertine formation that has preserved the archaeological remains. These consisted of lithic artefacts of the M-UP, faunal remains and charcoal. The lithics from the Upper Palaeolithic layer include blades and bladelets, while the Middle Palaeolithic section comprises much of the stratigraphy $(2.2 \mathrm{~m})$ and is mostly Levallois and Zagros Mousterian.

We plan to expand the excavation at Yawan rockshelter, and also to excavate a test trench in the cave-rockshelter of Charmi Sawar (Figure 1), another site that has been damaged by looters. Ongoing work includes the analysis, at the University of Cambridge, of 12 block samples of deposits for micromorphological analysis from the first three sites. We are also currently studying the lithic material from the Warwasi rockshelter.

By combining existing datasets with new fieldwork, the MUP Zagros Project will contribute to some of the major questions about the demographic, behavioural and cultural aspects of the Palaeolithic of Southwest Asia.

\section{Acknowledgements}

The MUP Zagros project is supported by the Iranian Cultural Heritage and Tourism Organization (ICHTO), and especially by H. Choubak, A. Sardari, A. Chaychi and N. Jalali. We also thank A. Felegari, former head (C) Antiquity Publications Ltd, 2017 
of ICHTO of the Kermanshah Province. We appreciate the assistance of A. Tahmasebi and S. Hourshid (the ICHTO representatives). Grant support was provided for this research by Gerda Henkel Stiftung, the German Academic Exchange Service (DAAD) and the European Union (Marie Curie project MUP-TransZagros). Special thanks go to Yousef Moradi. We also would like to thank a number of people who helped us on this project: F. Biglari (the National Museum of Iran), who kindly provided appropriate information about surveys; S. Münzel, B. Starkovich, M. Malina and H. Dibble. We thank D. Olszewski and R. Foley for valuable comments. Special thanks to T. Higham, Katerina Douka and Lorena Becerra Valdivia (PalaeoChron Project/ERC-2012-AdG-324139; Oxford Radiocarbon Accelerator Unit) for radiocarbon dating of the Eshkafte Razawar Cave excavation. We appreciate the members of the survey and excavation team: R. Naderi, N. Hariri and the Heydari family.

\section{References}

Biglari, F. \& S. Shidrang. 2016. New evidence of Paleolithic occupation in the western Zagros foothills, in K. Kopanias \& J. MacGinnis (ed.) The archaeology of the Kurdistan region of Iraq and adjacent regions: 29-38. Oxford: Archaeopress.

HeYdari, S. 1999. Late Quaternary climatic changes of the Kermanshah region on the basis of sedimentological evidence from the geological sections of the Sorkheh Lizeh and Tang-e Kenesht. Unpublished MA dissertation, Azad University of Najafabad.

Heydari-Guran, S. 2014. Palaeolithic landscapes of Iran (British Archaeological Reports international series 2568). Oxford: Archaeopress.

- 2015. Tracking Upper Pleistocene human dispersals into the Iranian Plateau: a geoarcheological model, in N. Sanz (ed.) HEADS 4 World Heritage Papers. Human origin sites and the World Heritage convention in Eurasia. Volume I: 40-54. Paris \& Mexico, D.F.: UNESCO.
Olszewski, D.I. \& H.L. Dibble. 1994. The Zagros Aurignacian. Current Anthropology 35: 68-75. http://dx.doi.org/10.1086/204242

Shidrang, S., F. Biglari, J.-G.A. Bordes $\&$ J. Jaubert. 2016. Continuity and change in the Late Pleistocene lithic industries of the central Zagros: a typo-technological analysis of lithic assemblages from Ghare-e Khar Cave, Bisotun, Iran. Archaeology, Ethnology \& Anthropology of Eurasia 44: 27-38. http://dx.doi.org/10.17746/ 1563-0110.2016.44.1.027-038

Smith, P.E.L. 1986. Palaeolithic archaeology in Iran (The American Institute of Iranian Studies Monograph 1). Philadelphia: The University Museum, University of Pennsylvania.

Tsanova, T. 2013. The beginning of the Upper Paleolithic in the Iranian Zagros: taphonomic approach and techno-economic comparison of Early Baradostian assemblages from Warwasi and Yafteh (Iran). Journal of Human Evolution 65: 39-64. http://dx.doi.org/10.1016/j.jhevol.2013.04.005 